\title{
MoMath: An Innovative Design of a Mobile based System for Supporting Primary School Mathematics in Tanzania
}

\author{
Deo Shao \\ Virtual Education and Technology Applications \\ University of Dodoma \\ Tanzania
}

\begin{abstract}
1. ABSTRACT
Mathematics is the most widely used subject in the world. Every career uses some sort of math. It is likely impossible for a country to be successful in science and technology arena without building a solid foundation of mathematics in its educational system. The current trend of performance in mathematics at both levels of educational systems in Tanzania is declining every year. The problem is reported to be at the elementary levels of education. There is a need to improve the consistent level of mathematical skills is Tanzania. The mobile phone penetration among students is very high and there is a need for proof of concept on how those devices could be applied for enhanced learning purposes in formal education. This study explores the use of mobile phones to support students learning activities in mathematics for primary and secondary schools. A MoMath prototype is proposed as blueprint of how SMS and IVR can be leveraged to support students in studying mathematics.
\end{abstract}

\section{General Terms}

Education, Technology

\section{Keywords}

Mobile phones; Mathematics; mLearning; Primary schools; Secondary schools;

\section{INTRODUCTION}

Science and engineering are significant components of human culture that embody some of the pinnacles of human achievement. Many recent calls for improvements in Tanzanian science education have focused on the need for science and engineering professionals to keep Tanzania self reliance in terms of expertness and professionalisms. Universities have been designing new science and engineering programmes to encourage students' enrolment. However, many of these new programmes fail to receive significant amount qualified students to join them due to the fact that one of criteria for joining them is a pass grade in mathematics.

Student's mathematics performance in Tanzania has been declining every year. The statistics of 2011 by Ministry of Education and Vocational Training of Tanzania (MOEVT), indicates that mathematics pass rate of form four national examination (CSEE) was $14.55 \%$ two percent less than 16.09 $\%$ mathematics pass rate in 2010 [1]. National Examination Council of Tanzania (NECTA) statistics of Standard VII national examination of 2013 shows the pass rate in Mathematics was 27\%, English 33\% and Sciences 46\% [2]. These staggering numbers of performance in Mathematics calls for serious action to rescue the situation as far as mathematics remains servant of other subjects.

Mathematics is one of the most important subjects covered in different levels from primary school to university level where it is taught as a paramount subject in studies involved in technical engineering. Scholars are suggesting Mathematics as a central part of the science applied in engineering and theoretical foundations of the world. A recent statistics from National Examination Council (NECTA) has shown a decline in students' performance in national examinations which according to this study has happened because of the low performance of mathematical learning styles at primary and secondary school levels.

The report by TWAWEZA [3] says $34 \%$ and $23 \%$ of secondary and primary schools respectively confess mathematics as a most difficult subject in their studies. Parents and teachers are pointing fingers to each blaming to be source of the massive failure in mathematics. The TWAWEZA report further that shortage ob textbooks in primary schools is $55 \%$ and $32 \%$ in secondary schools [3]. The critical shortfall of teachers in rural areas and inconsistent teachers' classroom attendance are also one of the myriad challenges facing education sector.

The survey by TWAWEZA reports shows that $8 \%$ and $12 \%$ of teachers in primary and secondary schools respectively do not attend their lessons [3]. The initiatives that tries to introduce computers in schools fails because of lack of experts and electric power.Currently, the coverage of national electricity supply grid is only $14 \%$ [4]. More than $70 \%$ of schools in Tanzania do not have electricity [5]. These are perhaps some of the reasons why there is a high failure rate in mathematics in Tanzania today.

According to Awang and Zakaria [6], studies from around the world have reported about weak mathematics background of university students as a result of poor foundation from the beginning.

\subsection{Formal Educational System in Tanzania}

According to statistics from UNESCO, in 2010, Tanzania's literacy rate was recorded at $67.8 \%$ Adult ( 15 years and older) and $74.6 \%$ Youth (15 to 24 years [7]. This could have been attributed by acute shortfall of educational resources such as teachers particularly in rural areas. The government through ministry of education (MOEVT) has been working hard to reduce the challenges facing the sector. One of the major steps taken by MOEVT is a induction of a transformation campaign coined as "Big Result Now (BRN)" which intends to catalyse the performance of the sector. The specific objectives of BRN in educational sector are to improve pass rate to at least $80 \%$ in primary and secondary school students, and to improve students abilities in mastering of 3R's (Reading, Writing and Arithmetic) at Standard I and II by implementing skills assessment and training teachers [8]. 
In order to realize the said BRN objectives, a lot need to be done. Technology particularly mobile technology is the corner stone in accomplishing the BRN objectives. BRN campaign has intentionally concentrated at the root level of Tanzanian education system to ensure the higher level gets qualified students. Table 1 presents the level of education in Tanzanian educational system.

Table 1: Levels in Tanzanian Educational system

\begin{tabular}{|l|l|l|}
\hline Level & Duration & Award \\
\hline Primary level, & $\begin{array}{l}\text { Seven } \\
\text { Years }\end{array}$ & $\begin{array}{l}\text { Certificate Of Primary } \\
\text { School Education } \\
\text { Examination (CPSEE) }\end{array}$ \\
\hline $\begin{array}{l}\text { Ordinary } \\
\text { level } \\
\text { secondary }\end{array}$ & Four Years & $\begin{array}{l}\text { Certificate Of Secondary } \\
\text { Education Examination } \\
\text { (CSEE) }\end{array}$ \\
\hline $\begin{array}{l}\text { High level } \\
\text { secondary, }\end{array}$ & Two Years & $\begin{array}{l}\text { Advanced Certificate Of } \\
\text { Secondary Education } \\
\text { Examination (ACSEE) }\end{array}$ \\
\hline Tertiary level & 3+ years & Bachelor Degree \\
\hline
\end{tabular}

\subsection{Mobile adoption in Tanzania}

Innovations in mobile and digital technologies are moving at a pace that poses a promising and an exciting future of various sectors in developing world. Mobile phone are now in the hands of more than $96 \%$ ( 6.8 billion) of the 7 billion global population, $128 \%$ in developed countries and $89 \%$ in developing countries [9]. In Tanzania the mobile penetration by the end of the year 2013 it was $61 \%$ [10]. These staggering numbers are indicators of the growth and reach of mobile phones around the world and Tanzania in particular.

Mobile phone is the most prevalent, readily available and affordable technology in low income communities. The fact that mobile phones are affordable to even low income community gives alerts that mobile technology could be used for support learning process. In the tremendous penetration of mobile technology adoption there is an opportunity to build a teaching system particularly mathematics through which a person can learn at his own pace.

\subsection{Motivation and Scope}

The impetus behind MoMath is to provide mobile learning experience for students in the developing world at low cost using existing infrastructure capacity. MoMath also leverage the existing GSM mobile phone networks, which have high penetration [9] even in some of the most rural and remote regions of the world. Moreover, MoMath is designed to support the government efforts of improving students' performance in mathematics particularly at lower levels.

\section{METHODOLOGY}

The basis of this exploratory study is an exhaustive literature review of conference proceedings, state-of-the-art- articles, technical reports and journals articles. A list of publications were exhaustively reviewed to identify and analyze mathematics interventions for students in developing countries particularly Tanzania. The articles that focused on the use of mobile phones and others on the learning theory concepts were chosen for review accordingly. The process of reviewing selected articles followed the 'literature review steps' defined by Oates [11], (Search->Obtain->Assess$>$ Read->Evaluate->Record->Review).

Despite the fact that, the study could not find enough academic literature that focuses on Tanzanian context, the reviewed reports still gave important insights on the current situation of the educational system. The reviewed literature from global perspectives on improving mathematics seems to be feasible in Tanzania context. However, we recommend studies to instantiate the global perspectives and evaluate them in local context.

Concepts gathered from the literature were conceptualized by designing a prototype (MoMath). March \& Smith's framework [12] was used to properly conceptualize and represent all the techniques in proposing the MoMath. Lastly, an evaluation study was carried to determine the applicability and suitability of the prototype in promoting the use of mobile technology to improve mathematics in primary schools.

\subsection{Related work}

Several scholars have considered using mobile technology in improving students' performance in mathematics.

Amiratashani [13] studied the impact of using mobile technology particularly Short Messaging Services (SMS) in supporting learning mathematics for Iranian students. The study found that the use of SMS have increased the motivation for students to learn mathematics and it also encouraged interaction among the students in the process of solving mathematical problems.

Kallo and Mohan [14] study that investigated the relationships between student performance and their usage of the mobile learning application found out mobile apps improves students performance.

Another study by Kallo and Mohan proposed the Mobile application for supporting students in learning mathematics. Although the application proposed by Kallo and Mohan [15] targeted high technology mobile devices, it has proved success in improving students learning activities.

Experience from the use of mobile phones to support learning in Malaysia [16], give hope that mobile learning could lead to paradigm shift in the essence of improving education outcomes in schools.

However, this study argues these adoptions of mobile technology to support mathematics learning should be taken with local context perspectives. Therefore, the adoption should first start by understanding the local settings and apply technology that suite the context. This study suggests a MoMath game based mathematics learning system for Tanzanian settings.

\section{PROPOSED SMS AND IVR BASED SYSTEM (MoMath)}

The process of integrating technology in classrooms particularly mathematics classrooms needs to be attempted with carefulness because of the nature of mathematics. Okita and Jamilian [17] mentions three key properties of technologies that can support improvement of students performance in mathematics. These key properties are technologies potentials that provide mathematics learners with motivation and engagement, informative feedback/assessment and visualization. Therefore integrating the aforementioned properties of technologies in math learning applications may lead to a conceptual integration and thus improve students' performance in mathematics.

Educational psychologist stipulates that people tend to learn better when they are competing amongst themselves [18].

Furthermore, game based learning has proved significant outcomes in tested cases [19]. 
Potential Learning Components/Activities that could take place in a mobile phone are for example gaming, self exercise and tutoring. Learning in mobile phones can happen in three modes, SMS mode, IVR mode and Mobile web browser. Table 2 describes different modes in which learning content can occur in mobile phone.

\subsection{Design of a MoMath game}

MoMath SMS based system is designed in terms of a learning game to allow multiple geographically distributed participants to play MoMath game at the same time.

Table 2 : Mobile learning operational modes

\begin{tabular}{|c|c|c|}
\hline Technology Framework & Delivery channel & Description \\
\hline $\begin{array}{l}\text { Short Messaging Service (SMS) } \\
\text { based system }\end{array}$ & $\begin{array}{l}\text { SMS } \\
\text { Unstructured Supplementary } \\
\text { Service Data (USSD) }\end{array}$ & $\begin{array}{l}\text { This is appropriate to rural areas where } 3 \mathrm{G} \\
\text { services coverage is still not full and most } \\
\text { of the people owns phones that can not } \\
\text { access internet }\end{array}$ \\
\hline Interactive Voice Response (IVR) & $\begin{array}{l}\text { Pre-recorded audio clips that can be } \\
\text { accessed through an offline mobile } \\
\text { phone call. }\end{array}$ & $\begin{array}{l}\text { Does not require internet connection. Ideal } \\
\text { for remote areas. }\end{array}$ \\
\hline Web browser based system & Mobile browser & $\begin{array}{l}\text { This requires mobile phones that can } \\
\text { access internet and it uses HTML5 to } \\
\text { design pages that are visualizable in } \\
\text { mobile web browsers. }\end{array}$ \\
\hline
\end{tabular}

\subsection{Components of a MoMath prototype}

The MoMath is composed of several components; these include a central server, mobigater, modem and cell phones. The actors of a MoMath are students, Moderators and teachers. Figure 1 depicts the components of the proposed MoMath.

\section{- Server}

A Linux box installed with apache web server which hosts open source software called Freedomfone1. Freedomfone software is customized to allow creation and share audio content using Interactive Voice Response (IVR), voicemail and SMS. In MoMath framework Freedomfone is used to manage routing of math quizzes in the format of text and audio.

- Mobigater and Modem

Mobigater handles voice calls routing and dialling. Modem handles the SMS sessions. In MoMath, Mobigater and Modem are used to handle IVR to students and SMS quizzes respectively.

\section{- Telecom Service} Providers

Enables communication between MoMath and other actors (Moderator and Student Help Center)

\section{- $\quad$ Student Help Center}

This is the student helpdesk which receives student's questions and suggest tips on how to answer them. It can be through SMS chat or Voice Chat.

\footnotetext{
${ }^{1}$ Freedomfone available at : http://freedomfone.org/
} 


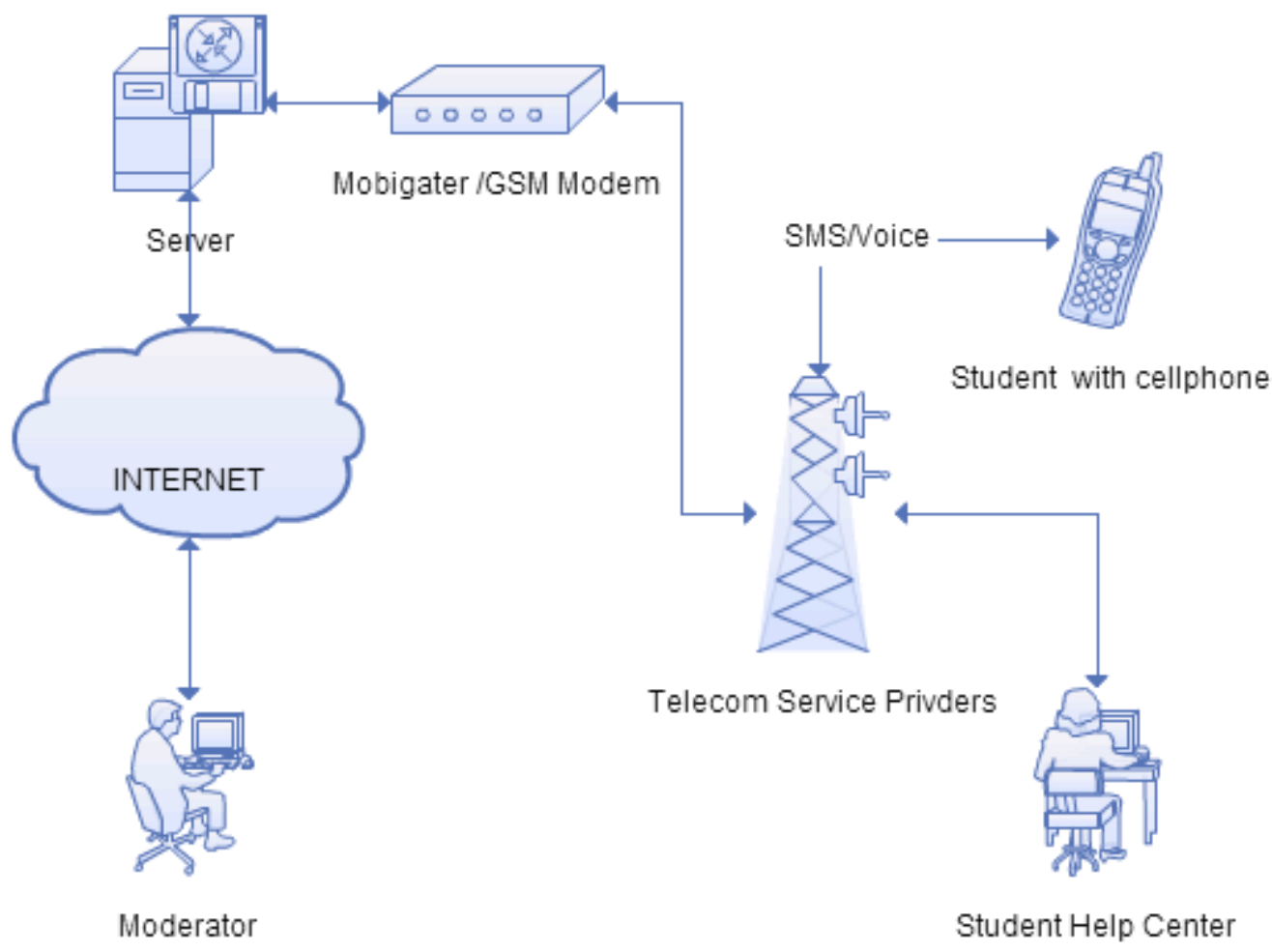

Figure 1: Components of a MoMath prototype

\subsection{How MoMath Operate}

- MoMath IVR lecturing session

MoMath offers a way for students to receive pre-recorded lectures in term of audio. When a student call a MoMath number, an audio content organised in multiple Voice Menus is played where by student can navigate using their phone keypad. For example an initial audio content will hear as, "Press 1 for Algebra lecture, Press 2 to speak with a teacher, Press 3 to record a message". The MoMath receives the student choice and perform the required action. However, the cost of listening to lecture will be the same as that of making normal voice call. In collaboration with Telecom companies this cost can be subsidized to help many students be able to access the MoMath lecture.

\section{- MoMath SMS quiz session}

MoMath SMS quiz session allow students to join questions sessions though SMS. This session is carried in terms of SMS chats where by a MoMath replies with pre-configured rules. Figure 2 shows the protocol of a MoMath quiz session. In the quiz session the following are few actions takes place.

1. Multiple participants send SMS with a C4M keyword to start a maths learning quiz session.

2. The MoMath reply the SMS by sending the SMS containing a list of topic to select

3. A participant reply with a topic code

4. The MoMath send different questions of the same level through SMS.
5. A participant replies the SMS by sending the correct answer.

6. The MoMath system receives answers and mark them before sending feedback

\section{- Quiz assessment}

When a student joins the MoMath system at first time a profile is created to track his progress. A mobile phone number is regarded as a student ID for this case. The students profile grows as he scores more credits and move to higher levels. In grading student attempts the following are considered.

1. The participant who answers first and correctly gets more credits for that question.

2. A participant moves on to the next level after successfully finishing set of questions of his current level.

3. At the end of everyday the highest scorer is announced through SMS to all the participants and also posted in the MoMath website.

4. The winners receive the SMS bundles as the prizes to encourage them keep playing the MoMath learning game.

5. Students can call student help center to ask for help. The MoMath personnel in charge or an offline pre-recorded lecture will be sent back inform of a voice call. The Mobigater handles these cases. 


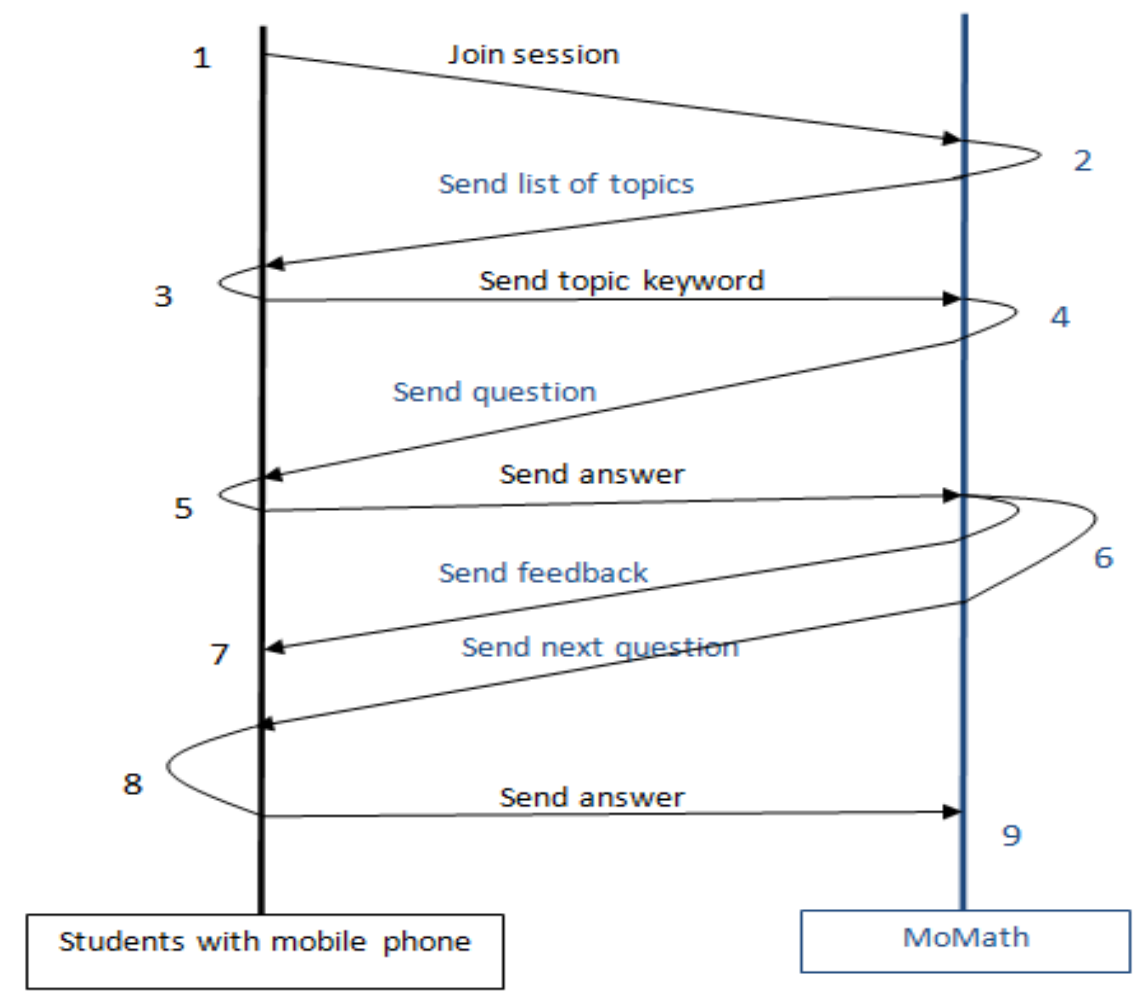

Figure 2 : MoMath SMS quiz session

\subsection{Evaluation of the MoMath}

Evaluation is an invaluable component of the research process. According to Hevner et al.[20], there are different ways in which IT artifacts can be evaluated, the ways are functionality, completeness, usability, consistency, accuracy, performance, reliability and how it fit with the context. The evaluation process of this study aimed at evaluating how MoMath fits with context of primary school mathematics in Tanzania a qualitative method.

The priority in participant's selection was given to the people who have knowledge of the educational system of Tanzania. Therefore we interviewed students, educational researchers, school administrators and teachers. We found contacts of the participants through colleagues and organizations websites. Online questionnaire, skype call interview, face to face interview and phone call interview was administered to garner opinions from various education stakeholders in Tanzania.

A total of 50 people participated in our evaluation study. Figure 3 presents the patterns of the feedback collected from MoMath stakeholders. Overall feedback from participants $52 \%$ agreed, $26 \%$ were not sure and $22 \%$ did not agree that MoMath could help to support learning mathematics in primary schools of Tanzania. However, in totality $75 \%$ participants indicated that MoMath will need government hand to takeoff and scale up in public schools.

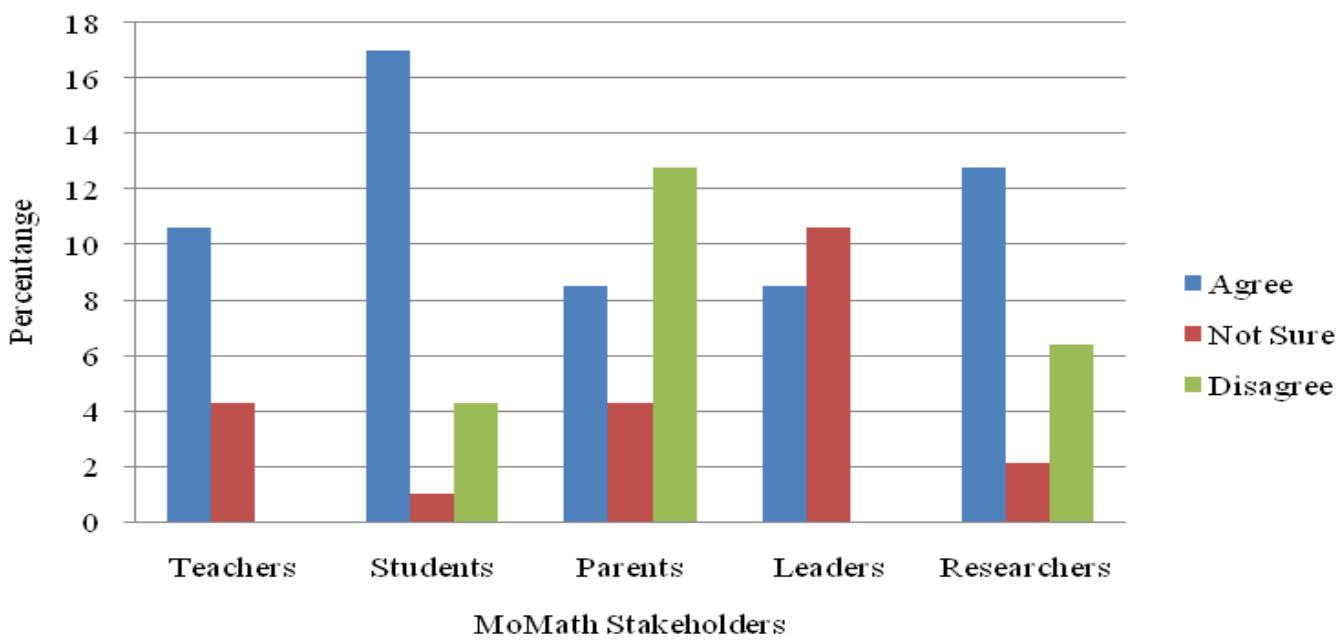

Figure 3: Stakeholders acceptance on MoMath 


\section{DISCUSSION}

The use of mobile technologies, specifically cheap short text messaging services (SMS), could significantly be leveraged to support learning styles at different levels of education system.

The artifact proposed in this paper can significantly promote efforts of improving learning of mathematics in primary schools. MoMath design can serve as a blueprint of the major implementation of a large scale mathematics learning framework. MoMath implementation could help effort of building strong foundation in mathematical skills from the grassroots of educational career of students. Moreover, it will increase mathematics learning hours to pupils by giving them time to play math quizzes and listen to lectures at their own pace. More importantly, MoMath will build the enthusiasm of students to mathematics therefore increase confidence for them on mathematics as part of their academia lives.

The components used to design the proposed prototype (MoMath) are based on open source technologies, which allow future development, which can be affordable and manageable by the economy of the developing regions.

\subsection{Conclusion and Future Work}

In this paper, we have investigated the use of mobile technologies in improving performance in mathematics for primary schools in Tanzania. The proposed prototype has been developed to test the applicability and usability of the available mobile and open source technologies in improving the students' participation in learning mathematics.

The realization of a great mobile phone adoption in Tanzania and the feasibility of using them for education purpose have important implications for educational reforms. This study calls for school leaders, parents, policy makers and other stakeholder in education to re-think and revisit ways of improving learning outcomes through the use of technology.

There is thus the need for pilot projects to adopt technology based models such as the prototype proposed in this research to improve the mathematics learning outcomes. Future work could draw attention in finding answers to critical questions such as, what type of content can give a added value for mathematics learner, what type of learning interventions are needed to enhance mathematical skills and abstract thinking in general, and how better solutions such as MoMath can be cascaded to masses.

\section{ACKNOWLEDGMENTS}

The author would like to thank Mr. Steven Edward for constructive comments in this work. Furthermore, the author expresses his gratitude to all respondents who participated in evaluating the artifact proposed in this work. Lastly but not the least, the author is grateful to IJCA reviewers for their instant and practical feedback.

\section{REFERENCES}

[1] MOEVT, "CSEEE : Report and Analysis of the Results," 2012.

[2] NECTA, "Primary School Pass Rate 2013," National Examination Council of Tanzania, 2014. [Online]. Available:

http://www.necta.go.tz/opendata/brn/index.php?mp=5. [Accessed: 28-Apr-2014]

[3] TWAWEZA, "Citizens report on the learning crisis in Tanzania,” Dar Es Salaam, 2013.
[4] WORLDBANK, "Only $14 \%$ of Tanzanians have electricity. What can be done?," 2013. [Online]. Available: http://blogs.worldbank.org/africacan/only-14of-tanzanians-have-electricity-what-can-be-done. [Accessed: 02-May-2014].

[5] ELearningAfrica, "Tanzania eLearning project bringing education to 1.5 million secondary students," 2014. [Online]. Available: http://www.elearningafrica.com/eLA_Newsportal/283/. [Accessed: 02-May2014].

[6] E. Awang, T.S. , Zakaria, "Integrating Computer Algebra Systems (CAS) into Integral Calculus Teaching and learning at the university," International Journal of Academic Research, vol. 3, no. 3, pp. 397-401, 2011.

[7] UNESCO, "Adult and Youth Literacy: National, regional and global trends, 1985-2015," 2011.

[8] URT, "Big Results Now ( BRN )," 2013.

[9] ITU, "The World in 2013 ICT Facts and Figures," 2013.

[10] TCRA, "Quartely Telecom Statistics Quarter 2 ( December 2013 ) Report 1 . Voice Prepaid Tariffs ( Without TAX )," 2013.

[11] B. J. Oates, "Researching Information Systems in Computing," in Reviewing the Literature, London: SAGE Publications, 2006, pp. 187-199.

[12] S. T. March and G. F. Smith, "Design and natural science research on information technology," Decision Support Systems, vol. 15, pp. 251-266, 1995.

[13] Z. Amiratashani, "M-learning in high school: The impact of using SMS in mathematics education-an Iranian experience," in Distance Learning and Education (ICDLE), 2010 4th International Conference, 2010, pp. $152-154$.

[14] V. Kalloo and P. Mohan, "Correlation between Student Performance and Use of an mLearning Application for High School Mathematics," in Advanced Learning Technologies (ICALT), 2011 11th IEEE International Conference, 2011, pp. $174-178$.

[15] V. Kalloo and P. Mohan, "MobileMath: An innovative solution to the problem of poor Mathematics performance in the Caribbean," Caribbean Teaching Scholar, vol. 2, no. 1, pp. 5-18, 2012.

[16] M. A. I. N. M. Alaysia, "M-LEARNING: A New Paradigm of Learning," International journal of computer science \& information Technology (IJCSIT), vol. 2, no. 4, pp. 76-86, 2010.

[17] S. Y. Okita and A. Jamalian, "Current challenges in integrating educational technology into elementary and middle school mathematics education," Journal of mathematics education at teachers college, vol. 2, no. 1, pp. 49-58, 2011.

[18] M. V Covington and C. L. Omelich, "Task-oriented versus competitive learning structures: Motivational and performance consequences.," Journal of Educational Psychology, vol. 76, no. 6, pp. 1038-1050, 1984.

[19] L. Messerschmidt, "Learning to play games using a PSObased competitive learning approach," Evolutionary Computation, IEEE Transactions, vol. 8, no. 3, pp. 280 288, 2004.

[20] J. P. Alan R. Hevner, Sudha Ram, Salavatore T. March, "Design Science Information," MIS Quarterly, vol. 28, no. 1 , pp. $75-105,2004$. 